\title{
Weighted log-linear models for service delivery points in Ethiopia: a case of modern contraceptive users at health facilities
}

Demeke Lakew Workie ${ }^{1 *}$, Dereje Tesfaye Zike ${ }^{1}$, Haile Mekonnen Fenta ${ }^{1}$ and Mulusew Admasu Mekonnen²

\begin{abstract}
Background: Ethiopia is among countries with low contraceptive usage prevalence rate and resulted in high total fertility rate and unwanted pregnancy which intern affects the maternal and child health status. This study aimed to investigate the major factors that affect the number of modern contraceptive users at service delivery point in Ethiopia.

Methods: The Performance Monitoring and Accountability2020/Ethiopia data collected between March and April 2016 at round-4 from 461 eligible service delivery points were in this study. The weighted log-linear negative binomial model applied to analyze the service delivery point's data.

Results: Fifty percent of service delivery points in Ethiopia given service for 61 modern contraceptive users with the interquartile range of 0.62. The expected log number of modern contraceptive users at rural was 1 . 05 (95\% Wald Cl: -1.42 to -0.68$)$ lower than the expected log number of modern contraceptive users at urban. In addition, the expected log count of modern contraceptive users at others facility type was 0.58 lower than the expected log count of modern contraceptive users at the health center. The numbers of nurses/midwives were affecting the number of modern contraceptive users. Since, the incidence rate of modern contraceptive users increased by one due to an additional nurse in the delivery point.

Conclusion: Among different factors considered in this study, residence, region, facility type, the number of days per week family planning offered, the number of nurses/midwives and number of medical assistants were to be associated with the number of modern contraceptive users. Thus, the Government of Ethiopia would take immediate steps to address causes of the number of modern contraceptive users in Ethiopia.
\end{abstract}

Keywords: Negative binomial, Number of contraceptive users, Service delivery points, Weighted log-linear

\section{Plain English summary}

In Ethiopia, there is a high total fertility rate and unwanted pregnancy due to low contraceptive prevalence rate. This study aimed to investigate the major factors that affect the number of modern contraceptive users at service delivery point in Ethiopia. The weighted log-linear negative binomial model applied to analyze the Performance Monitoring and Accountability2020/ Ethiopia data.

\footnotetext{
* Correspondence: demay_gu06@yahoo.com

${ }^{1}$ Statistics Department, Science College, Bahir Dar University, Bahir Dar, Ethiopia

Full list of author information is available at the end of the article
}

The 461 eligible service delivery points were in this study. Fifty percent of service delivery points in Ethiopia given service for 61 modern contraceptive users with the interquartile range of 0.62. Among different factors considered in this study, residence, region, facility type, the number of days per week family planning offered, the number of nurses/midwives and number of medical assistants were found to be associated factors for the number of modern contraceptive users in Ethiopia.

In conclusion, the Government of Ethiopia both regional and federal would take immediate steps to address the causes of the number of modern contraceptive users in Ethiopia.

(c) The Author(s). 2018 Open Access This article is distributed under the terms of the Creative Commons Attribution 4.0 International License (http://creativecommons.org/licenses/by/4.0/), which permits unrestricted use, distribution, and reproduction in any medium, provided you give appropriate credit to the original author(s) and the source, provide a link to the Creative Commons license, and indicate if changes were made. The Creative Commons Public Domain Dedication waiver (http://creativecommons.org/publicdomain/zero/1.0/) applies to the data made available in this article, unless otherwise stated. 


\section{Background}

Globally, each year, nearly 350,000 women die while another 50 million suffer illness and disability from complications of pregnancy and childbirth [1]. In developing countries, millions of sexually active women aged 15-49 want to avoid pregnancy and delay childbearing for at least 2 years or want to stop pregnancy and limit their family size but have an unmet need for family planning (FP) [2]. About 25\% of women who would like to postpone their next birth by 2 years do not currently use a contraceptive method. This need could be met by improving contraceptive knowledge and the supply of reproductive health services so that women can better plan their families [3]. It has been reported that Ethiopia is one among six countries that contribute to about $50 \%$ of the maternal deaths along with India, Nigeria, Pakistan, Afghanistan and the Democratic Republic of Congo [1]. The total fertility rate of Ethiopia is 4.6 children per woman, contraceptive prevalence rate (CPR) is only $36 \%$ and an unmet need for family planning is $22 \%$ for married women [4], 24\% of total women age 15-49 years [5] and $16.2 \%$ among all women aged 15-49 years [6]. If Ethiopia follows its current rate of growth, its population will double in the next 30 years, hitting 210 million by 2060 . For fertilities to fall to those low levels, increases the use of modern contraceptive methods and family planning service delivery points play a significant contribution especially in less developed countries including Ethiopia. At present, contraceptive methods which are free of cost is provided in both governmental and NGO health facilities in Ethiopia at hospitals, clinics, health centers, and health posts [7]. But, Ethiopia is among countries with low contraceptive prevalence rate, with only $36 \%$ [4]. This resulted in high total fertility rate and unwanted pregnancy which intern affects the maternal and child health status [8].

Current use of modern contraceptive methods is one of the indicators most frequently used to assess the success of family planning programs. In Ethiopia, the variations of modern contraceptive use observed among regions, place of residence, marital status, wealth index and other factors $[4,5]$. This situation indicated that the assumption of conditional independence of responses of individuals on the probability of contraceptive users who are living in the same area (cluster) given the covariates may not be longer valid. This indicates that current contraceptive use may be affected by unobserved regional and clustering effects at the different level of the factors [9]. The modern contraceptive prevalence rate in Ethiopia is varied from $1.4 \%$ in Somali to $50.1 \%$ in Addis Ababa across regions and $49.8 \%$ in Urban to 32.4 in rural via residence [4]. The success of any policy or family planning program intervention depends on a correct understanding of the socioeconomic, geographic, demographic, and behavioral factors which may influence the family planning health facilities and modern contraceptive users. It is believed that population growth and family planning health facilities are closely related concepts. The principal findings and recommendations for strengthening the modern contraceptive users are availability and access to services, health facilities readiness, staffing training and improving the quality of care $[10,11]$. Therefore, this study aimed to investigate the major factors that affect the modern contraceptive users at service delivery point in Ethiopia using weighted log-linear negative binomial model.

\section{Methods}

\section{Data source, sampling design, and sample size}

The PMA2020/Ethiopia-R4 data was collected by Addis Ababa University's School of Public Health at the College of Health Sciences (AAU/SPH/CHS), in collaboration with regional universities, the Federal Ministry of Health and the Central Statistics Agency under the aegis of the Bill \& Melinda Gates Institute for Population and Reproductive Health at the Johns Hopkins Bloomberg School of Public Health. The PMA2020/ Ethiopia project was applied a two-stage stratified sample selection and stratification was achieved by separating each region into urban and rural areas. A sample of 461 eligible service delivery points (SDP) was considered for this study. The data collection was conducted between March and April 2016 by trained women who attained a high school diploma or higher level of education using smartphones. The study area and data collection procedures revealed in Fig. 1 [12].

\section{Measurements}

The response variable for this study was defined as the total number of visitors for modern contraceptive users at service delivery points during the last complete month preceding the survey. The predictor variables that included in this study were Region, residence (rural and urban), type of health facility (Health center and others (include: Health post, Hospital, Clinic and Pharmacy/drug shop/retail), advanced facility (Yes or No), facility supports by CHVs (Yes or No), the number of opening days per a week to offer family planning (5 days or below and above 5 days), total number of doctors, total number of nurses/midwives, total number of health officers and total number of pharmacists [13]. Data were entered into STATA-12 and analyzed using SAS-9.2.

\section{Statistics analysis}

A common model for count data is the Poisson model by assuming that the distribution has mean and variance equally [14]. Often, this does not hold true in real data, the sample variance is considerably larger than mean called over-dispersion and rarely smaller called under- 

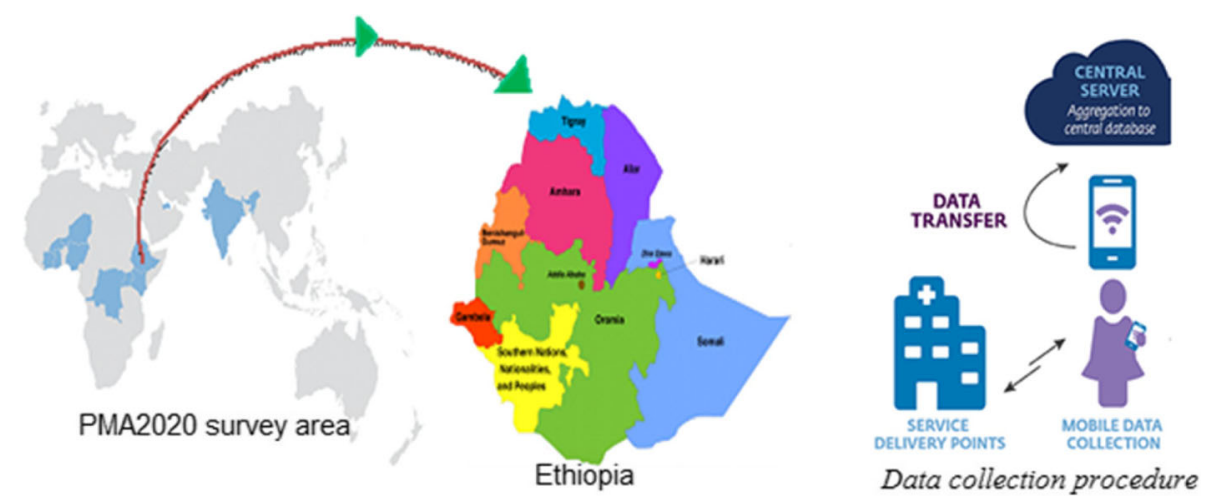

Fig. 1 Study area and data collection procedures

dispersion [15]. An over-dispersed model which assumes equidispersion can result in misleading inferences and conclusions, as over-dispersion can lead to the underestimation of parameter standard errors and falsely increase the significance of beta parameters [16, 17]. Hinde and Demetrio have published the issue of overdispersion in both binary and count data whereas more recently, Hayat and Higgins have published a review of Poisson regression and over-dispersion [18, 19].

Contraceptive user's data which is an example of count data, often exhibit larger variance than would be expected from the Poisson assumption [20]. There are a number of strategies for accommodating overdispersion. One of the approaches among a lot is a model in which $\mu$ was a random variable with a gamma distribution leading to a negative binomial distribution (NB) for the count data [20]. NB regression handles dispersion issues by modeling the dispersion parameter of the response variable. The relationship between variance and mean for NB distribution has the form of var. $\left(\mathrm{Y}_{\mathrm{i}}\right)=\mu_{i}+k \mu_{i}^{2}$, where $\mathrm{k}$ is a constant $[18,20,21]$. This is becausethe NB distribution accounts for further variance in count outcomes than the Poisson distribution through an additional shape parameter to the Poisson scale parameter [22]. In addition, classical methods of fitting statistical models canbe invalid in the presence of complex sampling designs involvingunequal weights, stratification or multi-stage sampling. To address this concern, there has been a considerable development of methods which do take account of complex designs [23-25]. One advantage of this approach is applicable to a very broad class of complex sampling schemes [26].

Along these lines, in this study researchers fitted a weighted log-linear negative binomial model for the number of modern contraceptive users from service delivery point as the data was over-dispersion due to cluster sampling.
The link function for negative binomial distribution is natural logarithm and then the model can be fitted as: $\log \left(\mu_{i}\right)=X \beta$, where $\mu_{i}$ be the expected number and variance of women who used the modern contraceptive method in $\mathrm{i}^{\text {th }} \mathrm{SDP}, \mathbf{X}$ is the predictors and $\beta$ is the parameter of the model. As the data was over-dispersed due to cluster sampling the model leads to the negative binomial with mean and variance of women who used the modern contraceptive method in $\mathrm{i}^{\text {th }}$ SDP. Here the data was collected from a disproportionate number of population size across nine regions grouped into two residences (rural and urban). Thus in this study, the weighted log-linear model was used that proposed by Agresti [27]. The advantage of the weighted analysis is that it removes the bias due to the unequal population sizes. Then the weighted log-linear model link function can be fitted as: $\log \left(\mu_{i j} /_{W_{i j}}\right)=X \beta$, where Wij be the total population size in $\mathrm{i}^{\text {th }}$ region and $\mathrm{j}^{\text {th }}$ residence, $\mu_{i j}$ be the expected number of women in $\mathrm{i}^{\text {th }}$ region and $\mathrm{j}^{\text {th }}$ residence at a given SDP, $\mathbf{X}$ is the predictors and $\beta$ is the parameter of the model. This model has an equivalent representation as: $\log \mu_{i j}-\log W_{i j}=X \beta$, where $-\log W_{i j}$ is the adjustment term to the log link of the mean called an offset [27]. As the maximum likelihood estimate is biased, restricted maximum likelihood technique was used for parameter estimation [28].

\section{Result}

\section{Descriptive statistics}

Among the study service delivery points (SDP) 206 (44. $7 \%)$ modern contraceptive providers were health centers whereas 255 (52.3\%) were collectively hospital, health post, health clinic, and pharmacy and retail outlet. Out of 10 , service delivery points seven had no community health volunteer (CHV) supports, of which more than half $166(52.2 \%)$ were located in the rural area. Among all family planning (FP) services provided at the study 
SDPs, the smallest were sterilization 76 (2.7\%) for female and $57(2.0 \%)$ for male) followed by IUD 268(9.6\%) whereas female condom and beads were null. The majority maternal services that offered by SDPs were antenatal care 406(28.3\%) followed by delivery 391 (27. 3\%). The majority 296 (66.8\%) of SDPs were offered FP below 5 days per week (Table 1).

The outcome of interest is the number of modern contraceptive users at SDPs during the last complete month preceding the survey. As a summary of the data, Fig. 2 shows a frequency plot, overall users, in all regions. We observe a highly skewed number of modern contraceptive users, (mean $=105.51$ and standard deviation $=195.12$ ), with $1.1 \%$ zero values.

Table 2 revealed that the median, quartiles and interquartile range statistic for quantitative variables including the response one. Fifty percent of service delivery points in Ethiopia had given service for 61 modern contraceptive users with the interquartile range of 0.62 . Fifty percent of service delivery points in the urban area had given service for 99 modern contraceptive users whereas 50\% SDPs in rural had given only to 45 modern contraceptive users. In addition, $50 \%$ of service delivery point in urban had 17 nurses whereas 50\% SDPs in rural had only 9.

\section{Factors associated with the number of modern contraceptive users at SDPs, Ethiopia}

The weighted Poisson and a negative binomial regression model were fitted. The deviance values for weighted Poisson and negative binomial regression model were 56821.95 and 351.08 respectively. Thus, the negative binomial regression model estimates the dispersion coefficient as a value 1.52 with a $95 \%$ CI $1.30-1.73$ signifying that it is more appropriate than the Poisson. Therefore, Table 3 below revealed the regression coefficients, standard errors, the Wald 95\% confidence intervals for the coefficients, chi-square tests and $p$-values for each of the model variables based on the analysis of ML parameter estimates.

The variables residence, region, the number of days per week FP offered, type of facility, the total number of

Table 1 Frequency distribution for qualitative predictors

\begin{tabular}{|c|c|c|c|c|c|}
\hline \multirow[t]{2}{*}{ Variables } & & & \multicolumn{2}{|c|}{ Residence area } & \multirow[t]{2}{*}{ Total } \\
\hline & & & Urban & Rural & \\
\hline \multirow[t]{2}{*}{ Type of facility } & Hospital Center & Count (\%) & $99(48.1)$ & 107(51.9) & $206(44.7)$ \\
\hline & Others $^{\mathrm{b}}$ & Count (\%) & $121(47.5)$ & $134(52.5)$ & 255(55.3) \\
\hline \multirow[t]{2}{*}{ Advanced Facility } & No & Count (\%) & 24(96.0) & $1(4.00)$ & $25(5.4)$ \\
\hline & Yes & Count (\%) & $196(45)$ & $240(55)$ & 436(94.6) \\
\hline \multirow[t]{2}{*}{ CHV supports } & No & Count (\%) & 152(47.8) & $166(52.2)$ & $318(69.0)$ \\
\hline & Yes & Count (\%) & 44(38.9) & $69(61.1)$ & $113(24.5)$ \\
\hline \multirow[t]{11}{*}{ Types of FP Provide ${ }^{a}$} & female sterilization & Count (\%) & $47(61.8)$ & 29(38.2) & $76(2.7)$ \\
\hline & male sterilization & Count (\%) & 39 (68.4) & 18(31.6) & $57(2.0)$ \\
\hline & implants & Count (\%) & 164(43.9) & $210(65.1)$ & $374(13.4)$ \\
\hline & IUD & Count (\%) & $152(56.7)$ & 116(43.3) & 268(9.6) \\
\hline & injectables & Count (\%) & $206(47.5)$ & $228(52.5)$ & 434(15.6) \\
\hline & pills & Count (\%) & $211(48.2)$ & 227(51.8) & $438(15.7)$ \\
\hline & progestin pills & Count (\%) & $181(52.5)$ & $164(47.5)$ & $345(12.4)$ \\
\hline & male condoms & Count (\%) & $210(48.5)$ & 223(51.5) & $433(15.5)$ \\
\hline & female condoms & Count (\%) & $8(80.0)$ & $2(20.0)$ & $10(0.4)$ \\
\hline & EC & Count (\%) & 202(58.0) & $146(42.0)$ & $348(12.5)$ \\
\hline & beads & Count (\%) & $1(50.0)$ & $1(50.0)$ & $2(0.1)$ \\
\hline \multirow[t]{4}{*}{ Type of maternal Services Provide ${ }^{a}$} & antenatal services & Count (\%) & $180(44.3)$ & $226(55.7)$ & $406(28.3)$ \\
\hline & delivery services & Count (\%) & 164(49.2) & $169(50.8)$ & $333(23.2)$ \\
\hline & postnatal services & Count (\%) & 173(44.2) & 218(55.8) & $391(27.3)$ \\
\hline & post-abortion services & Count (\%) & 161(53.0) & 143(47.0) & $304(21.2)$ \\
\hline \multirow[t]{2}{*}{ Number of days per week FP offered } & Below 5 days & Count $(\%)$ & 133(44.9) & $163(55.1)$ & 296(66.8) \\
\hline & Above 5 days & Count (\%) & $80(54.4)$ & $67(45.6)$ & $147(33.2)$ \\
\hline
\end{tabular}




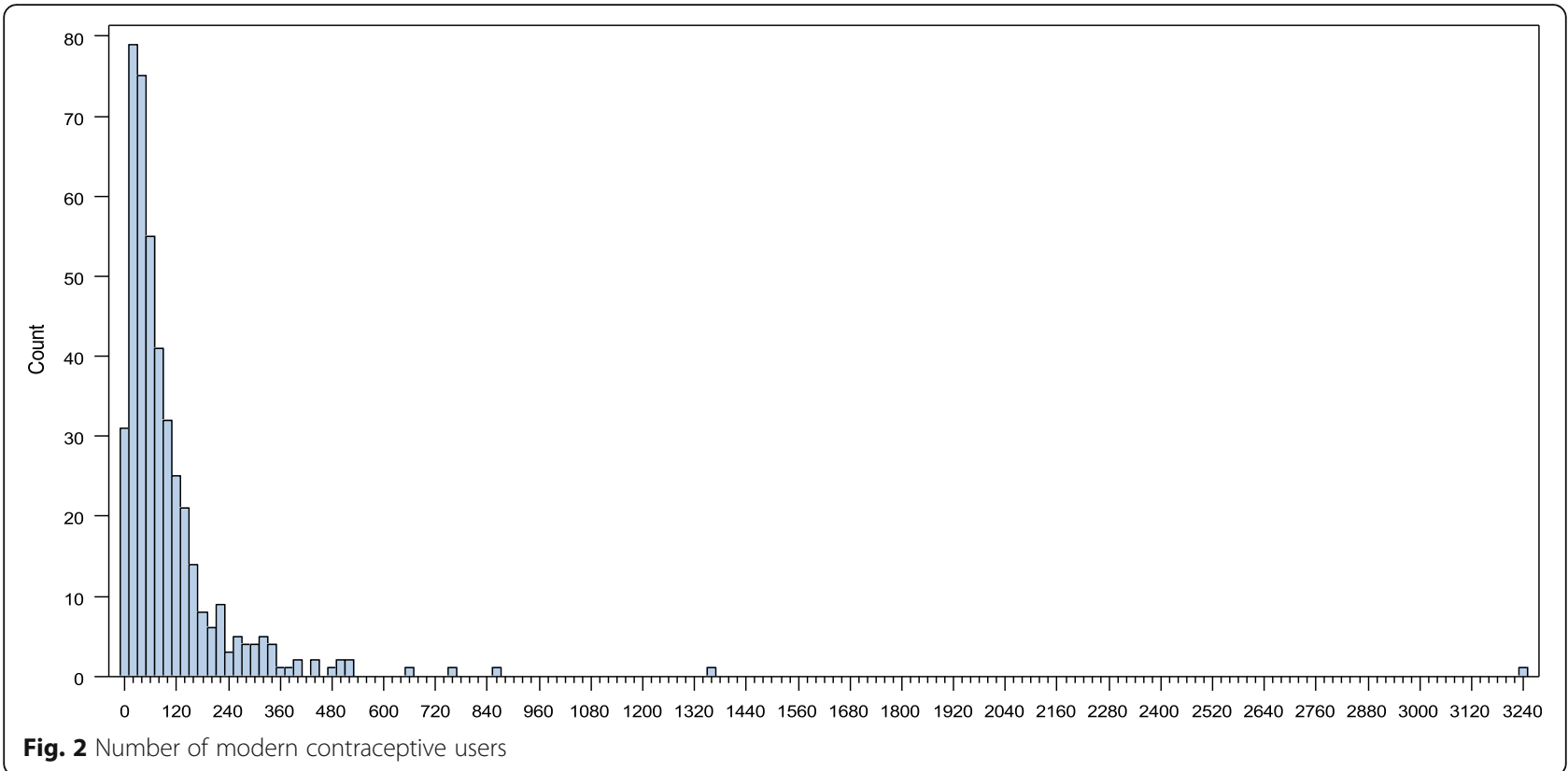

nurses/midwives, the total number of pharmacists and the total number of medical assistants were statistically significant. Keeping the other variables constant, the expected log count for a rural modern contraceptive user is 1.05 lower than the expected log count for urban modern contraceptive users. The expected log count of modern contraceptive users at others facility type was 0 . 58 lower than the expected log count of modern contraceptive users at the health center. The numbers of nurses/midwives were positively affecting the number of modern contraceptive users. Thus, the incidence rate of modern contraceptive users increased by more than one (1.01) as one additional nurse in the given service delivery point (Table 3 ).

\section{Discussion}

Fifty percent of service delivery points in Ethiopia had given service for 61 modern contraceptive users with the interquartile range of 0.62 . Considering the place of residence, urban modern contraceptive users were higher than that of rural modern contraceptive users. The contributors to this positive association may be the better socioeconomic status of women in urban, easy access to family planning services, cultural disparity compared to rural areas, and the high level of women literacy in urban areas. This result is in line with the study conducted at Afghanistan [29].

At the regional level, the disparity was observed among regions.

The expected $\log$ number of modern contraceptive users at Gambella, Harari, SNNP, and Somali was lower than that of Addis Ababa. This result is similar with the study in Ethiopia from EDHS data by Tesfaye. He recommended as efficient distribution of health care facilities offering family planning services in urban and rural residents are required and designed for family planning services targeting on Somali region greatly increase the rate of the number of contraceptive use [30]. This is because geographical variations in the number of modern contraceptive use have been found to be

Table 2 Descriptive statistic for numerical predictors

\begin{tabular}{|c|c|c|c|c|c|c|c|c|c|c|c|c|}
\hline \multirow[b]{2}{*}{ Variables } & \multicolumn{4}{|c|}{ Urban } & \multicolumn{4}{|c|}{ Rural } & \multicolumn{4}{|c|}{ Total } \\
\hline & M & Q1 & Q3 & IQR & M & Q1 & Q3 & IQR & M & Q1 & Q3 & IQR \\
\hline Number of Modern Contraceptive users & 99 & 45 & 174 & 0.59 & 45 & 21 & 74 & 0.56 & 61 & 29 & 123 & 0.62 \\
\hline Total number of doctors & 0 & 0 & 9 & 1.00 & 0 & 0 & 2 & 1.00 & 0 & 0 & 5 & 1.00 \\
\hline Total number of nurses/midwives & 17 & 7 & 44 & 0.73 & 6 & 0 & 12 & 1.00 & 9 & 2 & 28 & 0.87 \\
\hline Total number of health officers & 3 & 1 & 6 & 0.71 & 2 & 1 & 2 & 0.33 & 2 & 1 & 4 & 0.60 \\
\hline Total number of pharmacists & 2 & 1 & 5 & 0.67 & 0 & 0 & 2 & 1.00 & 1 & 0 & 3 & 1.00 \\
\hline Total number of medical assistants & 0 & 0 & 2 & 1.00 & 0 & 0 & 0 & - & 0 & 0 & 1 & 1.00 \\
\hline Total number of other medical staff & 4 & 1 & 14 & 0.87 & 2 & 1 & 4 & 0.60 & 2 & 1 & 8 & 0.78 \\
\hline
\end{tabular}

Key: M (median), Q1 (lower quartile), Q3 (upper quartile), IQR (inter quartile range) 
Table 3 Analysis of maximum likelihood parameter estimates

\begin{tabular}{|c|c|c|c|c|c|c|c|c|}
\hline \multirow[t]{2}{*}{ Variable } & \multirow[t]{2}{*}{ DF } & \multirow[t]{2}{*}{ Estimate } & \multirow{2}{*}{$\begin{array}{l}\text { Std } \\
\text { Err }\end{array}$} & \multicolumn{2}{|c|}{ 95\% Wald Cl } & \multirow{2}{*}{$\begin{array}{l}\text { Chi- } \\
\text { Square }\end{array}$} & \multirow[t]{2}{*}{ Pro $>$ ChiSq } & \multirow[b]{2}{*}{ Exp(Est) } \\
\hline & & & & Lower & Upper & & & \\
\hline Intercept & 1 & -3.64 & 0.60 & -4.81 & -2.47 & 37.28 & $0.00^{c}$ & \\
\hline Residence of SDP & 1 & & & & & $29.79^{b}$ & $0.00^{c}$ & \\
\hline Rural & 1 & -1.05 & 0.19 & -1.42 & -0.68 & 31.19 & $0.00^{c}$ & 0.35 \\
\hline \multicolumn{9}{|l|}{ Urban $^{\mathrm{a}}$} \\
\hline Region of SDP & 10 & & & & & $99.43^{b}$ & $0.00^{c}$ & \\
\hline Afar & 1 & 4.18 & 0.73 & 2.76 & 5.61 & 33.14 & $0.00^{c}$ & 65.65 \\
\hline Amhara & 1 & 1.07 & 0.49 & 0.11 & 2.03 & 4.78 & $0.03^{c}$ & 2.91 \\
\hline Benishangul Gumz & 1 & 0.23 & 0.65 & -1.03 & 1.50 & 0.13 & 0.72 & 1.26 \\
\hline Dire Dawa & 1 & 0.34 & 1.01 & -1.63 & 2.31 & 0.12 & 0.73 & 1.41 \\
\hline Gambela & 1 & -1.64 & 0.97 & -3.54 & 0.27 & 2.83 & 0.09 & 0.19 \\
\hline Harari & 1 & -0.02 & 0.84 & -1.68 & 1.63 & 0.00 & 0.98 & 0.98 \\
\hline Oromiya & 1 & 0.20 & 0.49 & -0.76 & 1.15 & 0.16 & 0.69 & 1.22 \\
\hline S.N.N.P & 1 & -0.30 & 0.40 & -1.09 & 0.49 & 0.56 & 0.45 & 0.74 \\
\hline Somali & 1 & -1.55 & 0.63 & -2.78 & -0.32 & 6.08 & $0.01^{c}$ & 0.21 \\
\hline Tigray & 1 & 0.39 & 0.50 & -0.59 & 1.36 & 0.60 & 0.4 & 1.47 \\
\hline \multicolumn{9}{|l|}{ Addis Ababa ${ }^{a}$} \\
\hline \# of days per week FP offered & 1 & & & & & $30.86^{b}$ & $0.00^{c}$ & \\
\hline Five or below days & 1 & -1.33 & 0.26 & -1.84 & -0.82 & 26.33 & $0.00^{c}$ & 0.26 \\
\hline \multicolumn{9}{|l|}{ Above days ${ }^{a}$} \\
\hline CHV Supporters & 1 & & & & & $0.54^{b}$ & 0.46 & \\
\hline No & 1 & -0.20 & 0.28 & -0.74 & 0.34 & 0.53 & 0.47 & 0.82 \\
\hline \multicolumn{9}{|l|}{$\operatorname{Yes}^{\mathrm{a}}$} \\
\hline Type of facility & 1 & & & & & $4.80^{b}$ & $0.03^{c}$ & \\
\hline Others & 1 & -0.58 & 0.26 & -1.08 & -0.08 & 5.13 & $0.02^{c}$ & 0.56 \\
\hline \multicolumn{9}{|l|}{ Health Center ${ }^{a}$} \\
\hline Total \# of doctors & 1 & -0.01 & 0.02 & -0.04 & 0.03 & 0.32 & 0.57 & 0.99 \\
\hline Total \# of nurses/midwives & 1 & 0.01 & 0.00 & 0.00 & 0.01 & 4.21 & $0.04^{c}$ & 1.01 \\
\hline Total \# of health officers & 1 & 0.04 & 0.04 & -0.04 & 0.11 & 0.87 & 0.35 & 1.04 \\
\hline Total \# of pharmacists & 1 & -0.16 & 0.03 & -0.22 & -0.10 & 29.18 & $0.00^{c}$ & 0.85 \\
\hline Total \# of medical assistants & 1 & -0.19 & 0.04 & -0.27 & -0.10 & 19.46 & $0.00^{c}$ & 0.83 \\
\hline Dispersion & 1 & 1.52 & 0.11 & 1.30 & 1.73 & & & \\
\hline
\end{tabular}

Key: $\mathrm{Cl}$ (Confidence Interval), ${ }^{a}$ (Reference category), ${ }^{\mathrm{b}}$ (Type 3 chi-square value), ${ }^{\mathrm{c}}$ (the relationship is significant at alpha value of 0.05 and or below), Exp(Est) (Exponentiating estimate)

influenced by community-level cultural beliefs like value attached to the child, the presence and quality of reproductive health services, shortage of midwives in most SDPs, remote geographical areas, and the presence of transport routes $[29,31-33]$. Whereas the expected log number of modern contraceptive users from Afar, Amhara, Benishangul Gumiz, Oromia, Tigray, Dire Dawa was higher than that of Addis Ababa. This result contradicts with the result done by [4] stated as the modern contraceptive prevalence rate in Ethiopia is varied from $1.4 \%$ in Somali to $50.1 \%$ in Addis Ababa across regions. This contradicts might be mainly due to confounding variables and slightly under estimation in regional towns. The main courses of under estimation may as regional women feeling shame to take contraceptive methods publically.

An increasing of nurse/midwives health officers, the expected log number of modern contraceptive users was increased by 0.01 and 0.04 respectively. Several studies have confirmed to the key role of nurses/midwives and health officers in providing guidance and effective counseling, resulting in an increased number of modern contraceptive users [34,35]. Other studies have reported an increase in a couple-year protection following the 
engagement of midwives in family planning services in service delivery points $[34,35]$. In Ethiopia, the involvement of health extension workers increased the contraceptive prevalence rate from 14 to $30 \%$ in 4 years $[34,35]$. In Iran, increased community participation consequent to the involvement of midwives and other stakeholders resulted in the number of modern contraceptive users this intern a decline in total fertility rate. In addition, the incident rate of the modern contraceptive user for below 5 days per week FP offered is 0.35 times compared to above 5 days per week FP offered. This is the fact that increasing the access days to offer modern contraceptive methods leads to increases the number of modern contraceptive users at SDPs.

\section{Conclusion}

This study was aimed to investigate the major factors that affect the number of modern contraceptive users at service delivery point in Ethiopia. Among different factors considered in this study, residence, region, facility type, the number of days per week family planning offered, number of nurses/midwives and number of medical assistants were found to be significantly associated factors for the number of modern contraceptive users in Ethiopia. The influence of these factors can be used to develop the strategies of increasing the number of modern contraceptive users at service delivery points in Ethiopia. The median number of experts at the rural area is very few compared to the urban area in Ethiopia. This intern leads the median number of modern contraceptive users at rural service delivery points in Ethiopia is very few. Few numbers of modern contraceptive users at service delivery points in Ethiopia might potentially lead to high total fertility rate which intern affects the maternal and child health status. Finally, this affects negatively the 2030 ambitious goals for universal access to sexual and reproductive health services, including family planning. Thus, the regional and federal Government of Ethiopia would take immediate steps to address causes of the number of modern contraceptive users in Ethiopia, especially in rural areas.

\section{Abbreviations}

AAU: Addis Ababa University; AOR: Adjusted odds ratio; CHS: College of Health Sciences; Cl: Confidence interval; COR: Crude odds ratio; EDHS: Ethiopia demographic health survey; ESA: Ethiopian statistical agency; FP: Family planning; GTP: Growth and transformation plan; LAM: Lactational amenorrhea method; OR: Odds ratio; PMA2020: Performance monitoring and accountability 2020; REs: Resident enumerators; SAS: Statistical analysis system; SPH: School of public health; SPSS: Statistical packages for social Sciences
}

\section{Acknowledgments}

The authors are indebted to Selamawit Desta, MSPH, MIA, Program Officer, PMA2020 give us permission access to the PMA2020/Ethiopia dataset.

\section{Funding}

The data collection funding was provided by the Bill \& Melinda Gates Foundation. No additional funding was sought to complete this article.

\section{Availability of data and materials}

The data set supporting the conclusions of this article is held by PMA2020/ Ethiopia Survey Project and the de-identified data may be made available based on written request and approval by PMA2020's coordinating center in Baltimore.

\section{Authors' contributions}

MA supervised the data collection. DL analyzed the data and wrote the manuscript. MA, DT, and HM critically edited the manuscript. All authors read and approved the final manuscript.

Ethics approval and consent to participate

It is not applicable because the data was collected by performance monitoring and accountability 2020 (PMA2020)/Ethiopia survey project.

\section{Consent for publication}

Participants were made aware in the consent form that the results of the study would be published but that no data would be presented to allow the identification of individuals.

\section{Competing interests}

The authors declare that they have no competing interests.

\section{Publisher's Note}

Springer Nature remains neutral with regard to jurisdictional claims in published maps and institutional affiliations.

\section{Author details}

${ }^{1}$ Statistics Department, Science College, Bahir Dar University, Bahir Dar, Ethiopia. ${ }^{2}$ PMA2020/Ethiopia project \& John Snow Inc (JSI) SEUHP/Ethiopia projecthttp://www.pma2020.org/Ethiopia.

Received: 9 November 2017 Accepted: 2 May 2018

Published online: 10 May 2018

\section{References}

1. Hogan MC, et al. Maternal mortality for 181 countries, 1980-2008: a systematic analysis of progress towards millennium development goal 5. Lancet. 2010;375(9726):1609-23.

2. Darroch, J.E., S. Singh, and J. Nadeau, Contraception: an investment in lives, health and development. Issues in brief (Alan Guttmacher Institute), 2011(5): p. 1-4.

3. Guengant J, May J. Africa 2050: African demography Washington. In: DC: centennial Group for Emerging Market Forum; 2013.

4. EDHS, Ethiopia demographic and health survey 2016: key indicators report. The DHS Program ICF, 2016.

5. PMA2020 and AAU. Detailed Indicator report: Ethiopia, 2014, BILL AND MELINDA GATES INSTITUTE for POPULATION and REPRODUCTIVE HEALTH, PMA2020 project, School of Public Health - Addis Ababa University. Baltimore: PMA2020; 2014.

6. Workie $\mathrm{DL}$, et al. A binary logistic regression model with complex sampling design of unmet need for family planning among all women aged (15-49) in Ethiopia. Afri Health Sci. 2017;17(3):637-46.

7. UN. World contraceptive use. New York: UN Department of Economic and Social Affairs, Population Division; 2011.

8. Berhane $Y$, Hailemariam D, Kloos H. Epidemiology and ecology of health and disease in Ethiopia. Addis Ababa: Shama books; 2006.

9. Tesfay Gidey Hailu. Determinants and cross-regional variations of contraceptive prevalence rate in Ethiopia: a multilevel modeling approach. J. Math. Stat. 2015;5(3):95-110. https://doi.org/10.5923/j.ajms. 20150503.01.

10. Miller $\mathrm{K}$, et al. Clinic-based family planning and reproductive health Services in Africa: findings from situation analysis studies. New York: Population Council, Inc; 1998

11. Lewis N, et al. AN ASSESSMENT OF CLINIC-BASED FAMILY PLANNING SERVICES IN KENYA. Nairobi: Division of Family Health; 1997. 
12. PMA2020. Performance monitoring and accountability 2020. 2017 [cited 2017 Sep.].

13. [Ethiopia], C.S.A. Ethiopia mini demographic, and health survey 2014. Addis Ababa: Central Statistical Agency, CSA; 2014

14. Molenberghs GVG. Models for discrete longitudinal data. New York: Library of Congress; 2005

15. Iddi S, Molenberghs G. A combined overdispersed and marginalized multilevel model. Computational Statistics and Data Analysis. 2012;56:1944-51.

16. Faddy M, Smith $D$. Analysis of count data with covariate dependence in both mean and variance. J Appl Stat. 2011;38(12):2683-94.

17. Hilbe JM. Negative binomial regression. Cambridge: Cambridge University Press; 2011.

18. Hinde, J. and C.G. Demétrio, Overdispersion: models and estimation Computational statistics \& data analysis, 1998. 27(2): p. 151-170.

19. Hayat MJ, Higgins M. Understanding Poisson regression. J Nurs Educ. 2014; 53(4):207-15.

20. Greenwood M, Yule GU. An inquiry into the nature of frequency distributions representative of multiple happenings with particular reference to the occurrence of multiple attacks of disease or of repeated accidents. J R Stat Soc. 1920;83(2):255-79.

21. Joe H, Zhu R. Generalized Poisson distribution: the property of mixture of Poisson and comparison with negative binomial distribution. Biom J. 2005; 47(2):219-29.

22. Booth JG, et al. Negative binomial loglinear mixed models. Stat Model. 2003;3(3):179-91.

23. Skinner $C$, Vallet $L-A$. Fitting log-linear models to contingency tables from surveys with complex sampling designs: an investigation of the CloggEliason approach. Sociol Methods Res. 2010;39(1):83-108.

24. Chambers RL, Skinner CJ. Analysis of survey data. University of Southampton UK: Wiley; 2003.

25. Lumley T. Analysis of complex survey samples. J Stat Softw. 2004;9(1):1-19.

26. Asparouhov T. Sampling weights in latent variable modeling. Struct Equ Model. 2005;12(3):411-34.

27. Agresti A. Wiley series in probability and statistics, Analysis of ordinal categorical data, second edition; 2002. p. 397-405.

28. Venables WN, Ripley BD. Random and mixed effects, in Modern applied statistics with S. New York: Springer; 2002. p. 271-300

29. Osmani AK, et al. Factors influencing contraceptive use among women in Afghanistan: secondary analysis of Afghanistan health survey 2012. Nagoya J Med Sci. 2015;77(4):551.

30. Hailu TG. Determinants and cross-regional variations of contraceptive prevalence rate in Ethiopia: a multilevel modeling approach. American Journal of Mathematics and Statistics. 2015;5(3):95-110.

31. Asiimwe JB, et al. Factors associated with modern contraceptive use among young and older women in Uganda; a comparative analysis. BMC Public Health. 2014;14(1):926.

32. Kragelund Nielsen $\mathrm{K}$, et al. Key barriers to the use of modern contraceptives among women in Albania: a qualitative study. Reprod. Health Matters. 2012; 20(40):158-65.

33. Stephenson $\mathrm{R}$, et al. Contextual influences on modern contraceptive use in sub-Saharan Africa. Am J Public Health. 2007;97(7):1233-40.

34. Jabbari $\mathrm{H}$, et al. Effectiveness of presence of physician and midwife in quantity and quality of family planning services in health care centers. J Family Community Med. 2014;21(1):1.

35. Alayande A, et al. Midwives as drivers of reproductive health commodity security in Kaduna state, Nigeria. Eur J Contracept Reprod Health Care. 2016; 21(3):207-12.

\section{Ready to submit your research? Choose BMC and benefit from:}

- fast, convenient online submission

- thorough peer review by experienced researchers in your field

- rapid publication on acceptance

- support for research data, including large and complex data types

- gold Open Access which fosters wider collaboration and increased citations

- maximum visibility for your research: over $100 \mathrm{M}$ website views per year

At BMC, research is always in progress.

Learn more biomedcentral.com/submissions 